\title{
Impact of PharmaNet-Based Admission Medication Reconciliation on Best Possible Medication Histories for Warfarin
}

\author{
Debbie Au, Hilary Wu, Cindy San, Doson Chua, Victoria Su, and Allison Kirkwood
}

\begin{abstract}
Background: Inaccurate documentation of medication histories may lead to medication discrepancies during hospital admissions. Obtaining a best possible medication history (BPMH) for warfarin can be challenging because of frequent dosage changes and nonspecific directions of use (e.g., "take as directed"). On February 27, 2012, the study hospital implemented an admission medication reconciliation (MedRec) process using a form that compiled the most recent 6 months of outpatient prescription dispensing history from a provincial electronic database called PharmaNet. It was unclear whether admission MedRec had improved the process of obtaining warfarin BPMHs and the quality of their documentation.
\end{abstract}

Objective: To compare the rates of complete warfarin BPMH documentation before and after implementation of PharmaNet-based admission MedRec.

Methods: A single-centre, retrospective chart review was conducted using the health records of patients receiving warfarin who were admitted to the hospital's Internal Medicine service before and after implementation of admission MedRec. The study periods were October 1, 2009, to February 26, 2012, and February 27, 2012, to July 31, 2014, respectively. The primary outcome was the rate of complete warfarin BPMH documentation during each period.

Results: Data were recorded for 100 patients in the pre-implementation phase and 100 patients in the post-implementation phase. The rates of complete warfarin BPMH documentation were $65 \%$ and $84 \%$ in these 2 phases, respectively $(p=0.002)$.

Conclusion: Implementation of PharmaNet-based admission MedRec was associated with a statistically significant increase in the rate of complete warfarin BPMH documentation.

Keywords: warfarin, medication reconciliation, PharmaNet, best possible medication history

\section{Can J Hosp Pharm. 2016;69(5):348-55}

\section{RÉSUMÉ}

Contexte : La consignation inexacte des schémas thérapeutiques peut mener à des divergences au chapitre des médicaments durant l'hospitalisation. Il peut être difficile d'établir un meilleur schéma thérapeutique possible (MSTP) pour la warfarine à cause de fréquents changements de posologie et de modes d'emploi imprécis (par exemple, " usage connu »). Le 27 février 2012, l'hôpital où s'est déroulée l'étude a mis en place un processus de bilan comparatif des médicaments (BCM) à l'admission. Celui-ci emploie un formulaire dressant la liste des médicaments d'ordonnance délivrés aux patients externes au cours des six derniers mois selon PharmaNet, une base de données numérique provinciale. On ignorait si les BCM à l'admission avaient amélioré le processus d'obtention et la qualité de la consignation des MSTP liés à la warfarine.

Objectif: Comparer les taux de MSTP relatifs à la warfarine parfaitement consignés avant et après la mise en place d'un processus de BCM à l'admission qui s'appuie sur PharmaNet.

Méthodes : Une analyse rétrospective des dossiers médicaux de patients menée dans un seul centre a été réalisée. Elle a porté sur les patients recevant de la warfarine et ayant été hospitalisés au service de médecine interne de l'hôpital avant ou après la mise en place d'un processus de BCM à l'admission (respectivement du $1^{\text {er }}$ octobre 2009 au 26 février 2012 et du 27 février 2012 au 31 juillet 2014). Le principal paramètre d'évaluation était le taux de MSTP relatifs à la warfarine parfaitement consignés pendant ces périodes.

Résultats : On a recueilli des données sur 100 patients hospitalisés avant la mise en place du processus et sur 100 patients hospitalisés après sa mise en place. Les taux de MSTP relatifs à la warfarine parfaitement consignés étaient de $65 \%$ avant la mise en place et de $84 \%$ après la mise en place $(p=0,002)$.

Conclusion : La mise en place d'un processus de BCM à l'admission s’appuyant sur les données de PharmaNet était associée à une augmentation statistiquement significative du taux de MSTP relatifs à la warfarine parfaitement consignés.

Mots clés : warfarine, bilan comparatif des médicaments, PharmaNet, meilleur schéma thérapeutique possible 


\section{INTRODUCTION}

$\mathrm{O}$ btaining an accurate and complete medication history is essential for patient safety. In their systematic review, Tam and others ${ }^{1}$ concluded that errors in prescription medication histories occurred in up to $67 \%$ of admissions. Of these errors, $39 \%$ were deemed to have the potential to cause moderate to severe harm as a result of unintentional changes to medication regimens. ${ }^{2}$

To address medication errors in hospitals, Accreditation Canada established a Required Organizational Policy in 2010 stating that medication reconciliation (MedRec) must be completed at the time of hospital admission. ${ }^{3}$ MedRec upon admission involves interviewing the patient and/or caregiver to obtain a best possible medication history (BPMH) of medications that were being taken before admission. This BPMH informs decisions about continuing, discontinuing, or changing the patient's medication regimen while in hospital. ${ }^{3}$

A lack of consistent BPMH documentation and variation in the MedRec process among clinicians can be problematic. In British Columbia, obtaining a BPMH is supported by the use of records from PharmaNet, an electronic database of all outpatient prescriptions dispensed in the province in the preceding 14 months, except for antiretroviral medications. On February 27, 2012, the study hospital, a tertiary institution in British Columbia, implemented admission MedRec using a PharmaNet-based form (Figure 1). This form compiled the medication dispensing history for the previous 6 months, as recorded in PharmaNet. The intent of the admission MedRec form was to assist physicians in reordering prior-to-admission medications and to minimize the risk of unintentional medication discrepancies and associated harm.

An accurate and complete MedRec process is critical for patients who are receiving warfarin. This anticoagulant has wide interpatient variation in dosing, and dosage adjustments are often required to achieve the target international normalized ratio (INR). ${ }^{4}$ Consequently, physicians rely on the BPMH to determine the appropriate warfarin dose for each admitted patient. However, obtaining warfarin BPMHs using PharmaNet records can be challenging, because the database records often contain nonspecific directions for use, such as "Take as directed" or "Doctor to adjust dose based on INR". Therefore, relying on PharmaNet alone to obtain warfarin BPMHs may lead to incomplete histories of warfarin use and the prescription of inappropriate warfarin dosages upon admission to hospital. These problems may delay achievement of target INR and increase the risk of warfarin-related adverse events because of subtherapeutic or supratherapeutic INR..$^{5-7}$ In a study of patients 65 years of age or older, hemorrhagic and thromboembolic risks were strongly associated with intensity of anticoagulation. ${ }^{5}$ Rates of bleeding increased 19-fold when the INR was supratherapeutic, and rates of thromboembolic events increased 7-fold when the INR was subtherapeutic. ${ }^{5}$ The Institute for Safe Medication Practices (US) has classified warfarin as a high-alert medication in the acute care setting. ${ }^{8}$

The purpose of this study was to evaluate the impact of PharmaNet-based admission MedRec on obtaining complete warfarin BPMHs.

\section{METHODS}

\section{Design}

This single-centre, retrospective chart review was approved by the UBC-Providence Health Care Research Ethics Board. The need for informed consent was waived.

\section{Study Population}

The study used a convenience sample of 100 patients in each phase who met the study's inclusion criteria. Patients were screened for eligibility using information in the hospital pharmacy database and patients' charts. Patients were included if they were 18 years of age or older, had been taking warfarin before admission, and had been admitted to the Internal Medicine service of the study hospital between October 1, 2009, and July 31, 2014 (pre-implementation phase: October 1, 2009, to February 26, 2012; post-implementation phase: February 27 , 2012 to July 31,2014 ).

The following exclusion criteria were applied: patient was a nonresident of British Columbia and would therefore not have a PharmaNet record; no MedRec form was completed in the post-implementation phase; patient was discharged or transferred to another facility within $24 \mathrm{~h}$ after admission; patient was admitted from another facility, was transferred to an intensive care unit during the admission, or underwent surgery during the admission; or patient was admitted with a thromboembolic or major bleeding event. Thromboembolic events were defined as ischemic stroke, transient ischemic attack, systemic embolism, deep vein thrombosis, or pulmonary embolism. Major bleeding events were defined as bleeding events that were fatal, intracranial, intraspinal, intraocular, or retroperitoneal; bleeding events that caused a decrease in hemoglobin of $20 \mathrm{~g} / \mathrm{L}$ or more; or bleeding that necessitated transfusion or required operation. ${ }^{9}$ Thromboembolic and major bleeding events were identified by reviewing progress notes and discharge summaries in patients' charts. Any identified events were further verified by reviewing radiologic imaging results, relevant laboratory data, and transfusion records.

\section{Outcomes}

The primary outcome was the rate of complete warfarin BPMH documentation upon admission. In the pre-implementation phase, complete warfarin BPMH documentation was defined as documentation of a warfarin regimen specifying both dose and frequency of administration on the admission note. In the 


\begin{tabular}{|c|c|c|c|}
\hline \multicolumn{4}{|c|}{$\begin{array}{l}\text { If You Received This Facsimile In Error, Please Call } \\
\text { Immediately }\end{array}$} \\
\hline $\begin{array}{l}\text { Medication Reconciliation C } \\
\text { (Page } 3 \text { of } 5 \text { ) } \\
\text { PHC-PH146 }\end{array}$ & Orders & $\begin{array}{l}\text { Birthdate: } \\
\text { PHN: }\end{array}$ & Gender: \\
\hline \multicolumn{3}{|c|}{ Medication History } & Request medical interpreter: \\
\hline $\begin{array}{l}\text { Medications as per PharmaNet } \\
\text { on }\end{array}$ & $\begin{array}{l}\text { Verified with: } \\
\square \text { patient }\end{array}$ & $\square$ other: & Medication Orders \\
\hline $\begin{array}{l}\text { TRAMADOL HCLIACETAMINOPHEN 37.5-325MG } \\
\text { TABLET } \\
\text { TAKE } 1 \text { TABLET FOUR TIMES A DAY AS NEEDED } \\
2015 \text { Jun } 29 \text { Qty: } 60 \text { Filled } \\
\text { CPSD: } \\
\text { [Max Dally Dose: } 4 \text { per Pharmanet] }\end{array}$ & $\begin{array}{l}\square \text { Taking differently ( } \\
\square \text { per PharmaNet } \\
\square \text { No longer taking } \\
\text { Last taken at: }\end{array}$ & $\square$ Unable to verify & $\begin{array}{l}\square \text { Give as per verified history } \\
\square \text { Give as per PharmaNet } \\
\square \text { Discontinue } \\
\square \text { Change to: }\end{array}$ \\
\hline $\begin{array}{l}\text { WARFARIN SODIUM } 2.5 \text { MG TABLET } \\
\text { TAKE AS DIRECTED ACCORDING TO INR RESULTS } \\
2015 \text { Jun } 17 \text { Qty: } 100 \text { Filled } \\
\text { CPII: } \\
\text { [Max Dally Dose: } 1 \text { per Pharmanet] }\end{array}$ & $\begin{array}{l}\square \text { Taking differently ( } \\
\square \text { per PharmaNet } \\
\square \text { No longer taking } \\
\text { Last taken at: }\end{array}$ & $\square$ Unable to verify & $\begin{array}{l}\square \text { Give as per verified history } \\
\square \text { Give as per PharmaNet } \\
\square \text { Discontinue } \\
\square \text { Change to: }\end{array}$ \\
\hline $\begin{array}{l}\text { ROSUVASTATIN CALCIUM } 20 \text { MG TABLET } \\
\text { TAKE } 1 \text { TABLET NIGHTLY AT BEDTIME } \\
2015 \text { Jun } 16 \text { Qty: } 90 \text { Filled } \\
\text { CPSiD: } \\
\text { [Max Daily Dose: } 1 \text { per Pharmanet] }\end{array}$ & $\begin{array}{l}\square \text { Taking differently } \\
\square \text { per PharmaNet } \\
\square \text { No longer taking } \\
\text { Last taken at: }\end{array}$ & $\square$ Unable to verify & $\begin{array}{l}\square \text { Give as per verified history } \\
\square \text { Give as per PharmaNet } \\
\square \text { Discontinue } \\
\square \text { Change to: }\end{array}$ \\
\hline $\begin{array}{l}\text { RAMIPRIL } 5 \text { MG CAPSULE } \\
\text { TAKE } 1 \text { CAPSULE DAILY } \\
2015 \text { Jun } 16 \text { Qty: } 90 \text { Filled } \\
\text { CPSID: : } \\
\text { [Max Daily Dose: } 1 \text { per Pharmanet] }\end{array}$ & $\begin{array}{l}\square \text { Taking differently } \\
\square \text { per PharmaNet } \\
\square \text { No longer taking } \\
\text { Last taken at: }\end{array}$ & $\square$ Unable to verify & $\begin{array}{l}\square \text { Give as per verified history } \\
\square \text { Give as per PharmaNet } \\
\square \text { Discontinue } \\
\square \text { Change to: }\end{array}$ \\
\hline $\begin{array}{l}\text { ALLOPURINOL } 300 \text { MG TABLET } \\
\text { TAKE } 1 \text { TABLET DAILY } \\
2015 \text { Jun } 16 \text { Qty: } 90 \text { Filled } \\
\text { CPSID: } 1 \text { per Pharmanet] } \\
\text { [Max Daly Dose: }\end{array}$ & $\begin{array}{l}\square \text { Taking differently ( } \\
\square \text { per PharmaNet } \\
\square \text { No longer taking } \\
\text { Last taken at: }\end{array}$ & $\square$ Unable to verify & $\begin{array}{l}\square \text { Give as per verified history } \\
\square \text { Give as per PharmaNet } \\
\square \text { Discontinue } \\
\square \text { Change to: }\end{array}$ \\
\hline $\begin{array}{l}\text { Medication History taken by: } \\
\square \text { Prescriber or } \\
\text { Designation }\end{array}$ & & $\begin{array}{l}\text { Prescriber: } \\
\text { Date }\end{array}$ & Time \\
\hline $\begin{array}{l}\text { Signature/lnitials: } \\
\text { Reauested bv: }\end{array}$ & $\underline{-}$ & $\begin{array}{l}\text { Signature } \\
\text { Printed Name }\end{array}$ & College ID \\
\hline & & $\begin{array}{r}\text { PLACE ORIGINAL } \\
\text { FAXA }\end{array}$ & $\begin{array}{l}\text { IN ORDERS SECTION OF CHART } \\
\text { L PAGES TO PHARMACY }\end{array}$ \\
\hline
\end{tabular}

Figure 1. Extract from a sample PharmaNet-Based medication reconciliation form completed at the time of admission. 
post-implementation phase, complete warfarin BPMH documentation was defined as documentation of a warfarin regimen specifying both dose and frequency of administration on the MedRec form, the admission note, or both.

\section{Data Collection}

Data were collected from the hospital's electronic clinical databases and health records. The following data were collected for each patient: demographic characteristics, the prior-toadmission warfarin regimen as documented on the admission note and/or the MedRec form, the length of hospital stay, and any thromboembolic or major bleeding events that occurred during the admission. For patients in the post-implementation group, warfarin regimens with unclear directions in the PharmaNet database (e.g. "Take as directed") were also recorded.

\section{Statistical Analysis}

All statistical analyses were performed using the XLSTAT software package for Microsoft Excel (Microsoft Corporation, Redmond, Washington).

In the primary outcome analysis, the pre- and post-implementation rates of complete warfarin BPMH documentation were compared with the $\chi^{2}$ test.

In addition, data from the post-implementation phase were analyzed to assess the influence of PharmaNet records on the MedRec process. More specifically, the $\chi^{2}$ test was used to compare the rates of complete warfarin BPMH documentation on the MedRec form between patients with clear versus unclear (e.g., "Take as directed") warfarin regimens in the PharmaNet database.

It was observed that clinicians commonly documented the dose but not the frequency of administration for warfarin, which we assumed was because warfarin was to be given once daily. Therefore, in a post hoc analysis, the $\chi^{2}$ test was also used to compare pre- and post-implementation rates of BPMH documentation considering only the documentation of warfarin dose.

For all statistical analyses, $p$ values less than 0.05 were considered statistically significant.

\section{RESULTS}

A total of 543 patients were screened, of whom 100 patients were included in the pre-implementation phase and 100 patients in the post-implementation phase (Figure 2). The demographic and clinical characteristics were similar between the 2 groups (Table 1).

The rate of complete warfarin BPMH documentation (with a record of both dose and frequency of administration) was significantly higher in the post-implementation phase than the pre-implementation phase $(84 \%$ versus $65 \%, p=0.002)$ (Table 2). In the post hoc comparison based on documentation of only the dose of warfarin, there was a smaller but nonetheless statistically significant increase in the rate of complete warfarin BPHM documentation after MedRec was implemented (81\% versus $91 \%, p=0.042$ ).

Of the 100 patients included in the post-implementation phase, 38 had unclear warfarin regimens in the PharmaNet database, and 62 had clear regimens. Complete warfarin BPMHs were documented on the MedRec form for 11 (29\%) of the 38 patients with unclear PharmaNet records and $54(87 \%)$ of the 62 patients with clear PharmaNet records $(p<0.001)$ (Figure $3)$. For $23(61 \%)$ of the 38 patients with unclear warfarin regimens in the PharmaNet database, the clinician checked off the "per PharmaNet" box on the MedRec form (Figure 1), thereby indicating that the patient's prior-to-admission regimen was consistent with the PharmaNet record; the resulting BPMH was thus incomplete.

The rates of thromboembolic and major bleeding events during the hospital stay were similar between the pre- and postimplementation phases $(0 \%$ versus $0 \%$ for thromboembolic events and $2 \%$ versus $1 \%$ for major bleeding events). The mean length of hospital stay was also similar for the 2 phases (Table 1 ).

\section{DISCUSSION}

The goal of implementing PharmaNet-based admission MedRec was to facilitate a systematic approach to gathering and documenting BPMHs, to prevent duplication of work across disciplines, and to consolidate BPMH documentation into one consistent location within the patient chart. ${ }^{10}$

Obtaining a complete and accurate BPMH is essential to preventing drug-related problems during hospital admission, ${ }^{11}$ and previous studies evaluating electronically generated medication checklists or MedRec systems have shown a reduction in medication discrepancy rates. ${ }^{12-15}$ Obtaining a BPMH is especially important for patients who are taking warfarin, because the complete BPMH serves as a clear record of the patient's home regimen and allows the clinician to make informed decisions when adjusting the dosage on the basis of INR results.

This study evaluated the impact of PharmaNet-based admission MedRec by comparing the rates of complete warfarin BPMH documentation before and after its implementation. The results indicated a statistically significant increase in the rate of complete warfarin BPMH documentation after MedRec was implemented. These observations suggest that the MedRec form improved BPMH documentation, and it is likely that such improvements will be helpful for clinicians caring for patients in hospital.

Although the study results indicated that integration of PharmaNet records into the MedRec form was useful for BPMH documentation, analysis of the post-implementation data showed that the clarity of warfarin instructions provided in the PharmaNet database influenced the quality of warfarin BPMHs. 


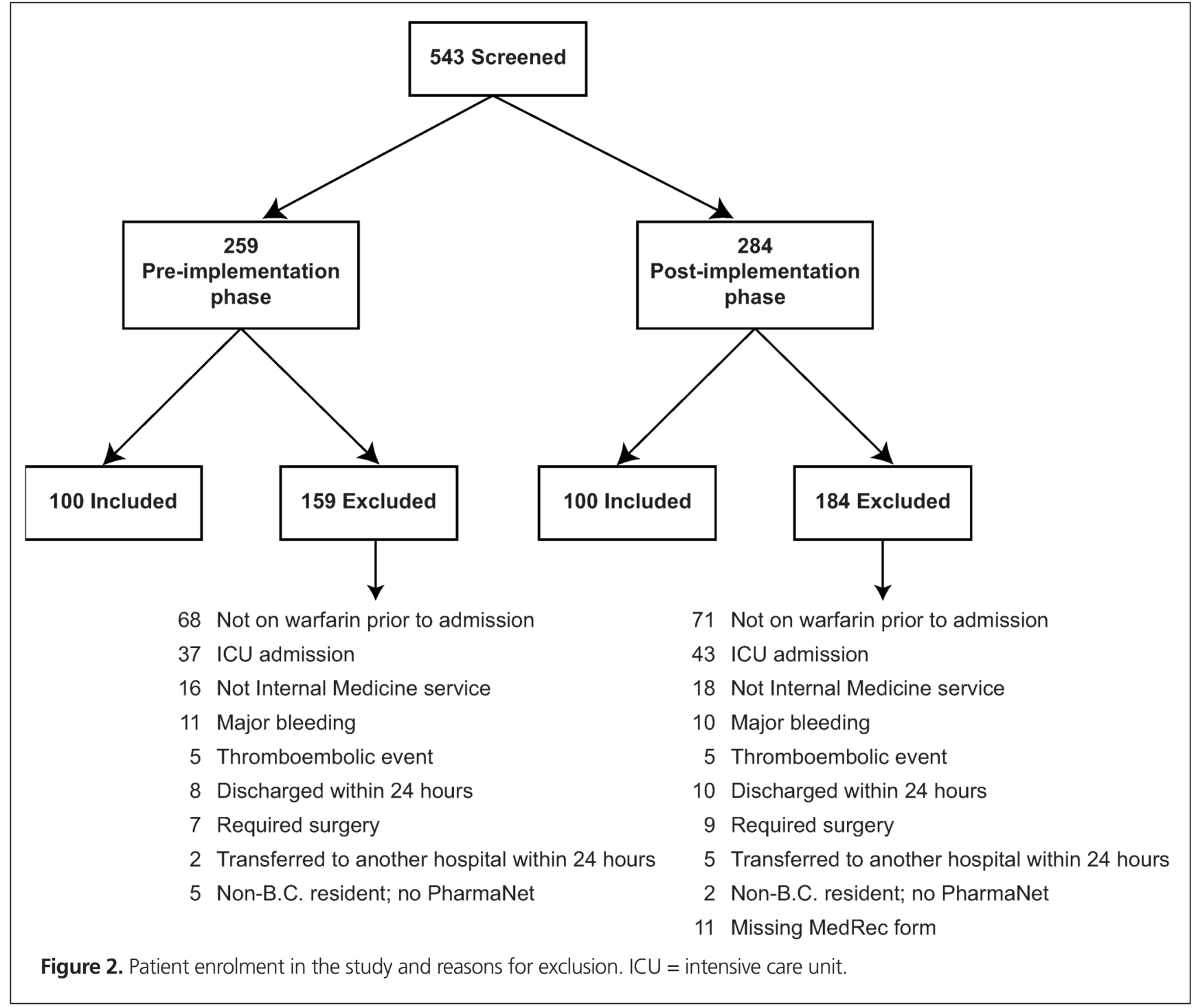

Table 1. Demographic and Clinical Characteristics of Study Participants

\begin{tabular}{lcc} 
& \multicolumn{2}{c}{ Phase of Study; \% of Patients* } \\
\cline { 2 - 3 } Characteristic & $\begin{array}{c}\text { Before MedRec } \\
\text { Implementation } \\
(\boldsymbol{n}=\mathbf{1 0 0})\end{array}$ & $\begin{array}{c}\text { After MedRec } \\
\text { Implementation } \\
(\boldsymbol{n}=100)\end{array}$ \\
\hline Age (years) (median and IQR) & $73(63-84)$ & $75(67-83)$ \\
Sex, male & 60 & 52 \\
Spoken language, English & 76 & 80 \\
Length of stay (days) (mean \pm SD) & $9 \pm 7$ & $10 \pm 8$ \\
No. of home medications (median and IQR) & $10(7-13)$ & $10(7-13)$ \\
Indication for warfarin & & 72 \\
Atrial fibrillation & 75 & 11 \\
Venous thromboembolism & 11 & 12 \\
Replacement of mechanical valve & 10 & 5 \\
Other† & 4 & \\
\hline IQR = interquartile range, MedRec = medication reconciliation, SD = standard deviation. \\
* Except where indicated otherwise. \\
tPrior transient ischemic attack, prior left ventricle thrombus, peripheral vascular disease.
\end{tabular}


Table 2. Data for Primary Outcome: Completeness of Warfarin BPMH Documentation

\begin{tabular}{|c|c|c|c|}
\hline \multirow[b]{2}{*}{ Information Recorded in BPMH } & \multicolumn{2}{|c|}{ Phase of Study; \% of Patients* } & \multirow[b]{2}{*}{$p$ Value } \\
\hline & $\begin{array}{l}\text { Before MedRec } \\
\text { Implementation } \\
(n=100)\end{array}$ & $\begin{array}{l}\text { After MedRec } \\
\text { Implementation } \\
(n=100)\end{array}$ & \\
\hline Dose & 81 & 91 & 0.042 \\
\hline Frequency & 66 & 86 & 0.001 \\
\hline Both dose and frequency* & 65 & 84 & 0.002 \\
\hline
\end{tabular}

BPMH = best possible medication history, MedRec = medication reconciliation.

*This constitutes complete warfarin BPMH documentation

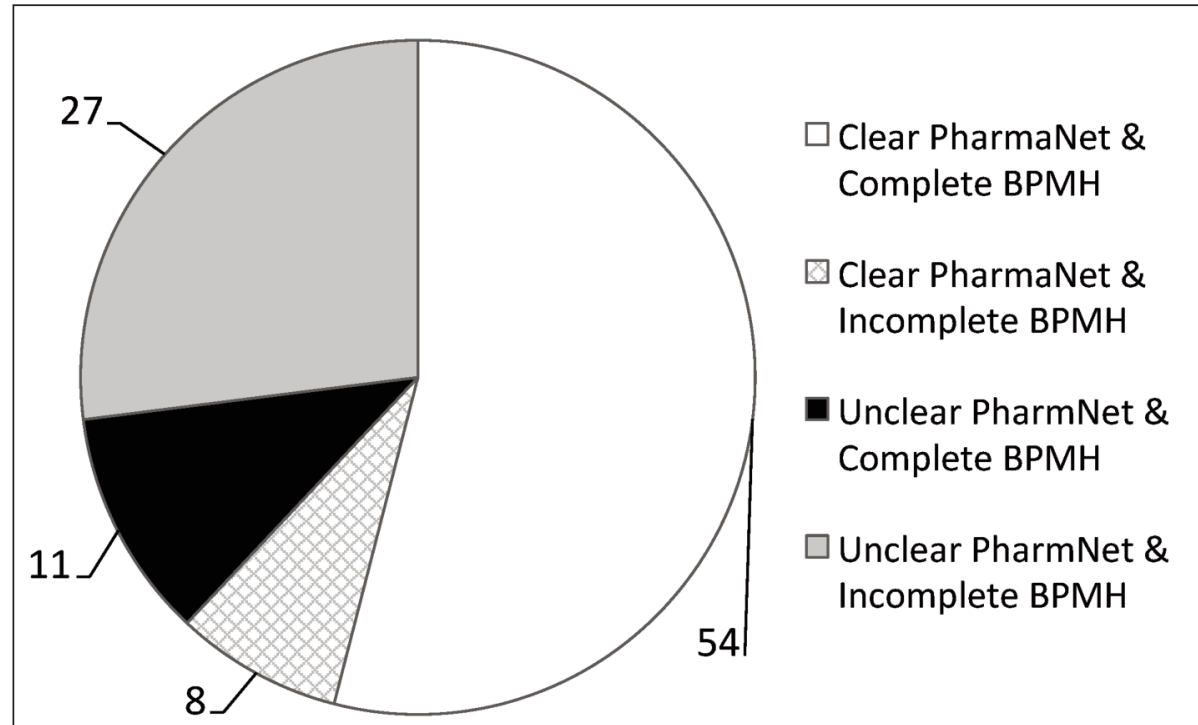

Figure 3. Clarity of PharmaNet entry and documentation of warfarin in the best possible medication history (BPMH) for patients in the post-implementation group.

PharmaNet records with nonspecific directions for warfarin administration were associated with higher rates of warfarin BPMHs that lacked documentation of the dose or frequency of administration. For most patients with incomplete warfarin BPMHs, the incomplete documentation was a direct result of reliance on unclear PharmaNet records. Specifically, the clinician documented on the MedRec form that the patient was taking warfarin as per the directions on PharmaNet, but those PharmaNet instructions were unclear. This finding suggests that there may be overreliance on PharmaNet records, rather than interviews with the patient or caregiver, when obtaining BPMHs.

British Columbia's PharmaNet database offers clinicians an additional resource when obtaining BPMHs. However, it is only a dispensing record and may not represent actual home use of medications. Therefore, clinicians must verify the accuracy of PharmaNet information when obtaining the BPMH. This requirement was confirmed by a study conducted in 2005 and 2006, which reported that the availability of PharmaNet did not lower the rate of unintentional medication discrepancies upon admission to a $\mathrm{BC}$ hospital relative to the rate in an Ontario hospital, where a provincial prescription database was not available (60\% versus 54\%). ${ }^{16}$ Furthermore, a study conducted in 2003 at St Paul's Hospital in Vancouver showed a 71\% discrepancy rate between medication histories based on information in PharmaNet and those obtained by pharmacists during patient interviews. ${ }^{17}$ Therefore, although PharmaNet is an accessible resource for $\mathrm{BC}$ clinicians, vigilance is required when reviewing PharmaNet records, particularly by clinicians who are obtaining warfarin BPMHs. In a study conducted in 2011, which compared regimens recorded in BPMHs obtained by pharmacists with regimens recorded in PharmaNet, warfarin had the fourth highest rate of discrepancies: $82.5 \%$ of the PharmaNet records for warfarin had dosage errors, frequency errors, and/or unclear instructions. ${ }^{18}$

In addition to overreliance on PharmaNet records, lack of time, staffing resources, and training may contribute to incomplete BPMHs. MedRec at the tertiary hospital where this study was conducted is performed primarily by admitting physicians, with further review by pharmacists. Pharmacists are medication experts and could be valuable assets to the clinical team in 
conducting MedRec during admission. In previous studies, pharmacist-acquired BPMHs were more accurate, were more likely to include nonprescription products, and increased MedRec completion rates for admitted patients relative to those acquired by physicians or nurses. ${ }^{19-25}$ Instead of pharmacists retrospectively clarifying medication discrepancies, early involvement of pharmacists in the MedRec process is a more proactive approach to minimizing medication errors and improving the efficiency of order processing. A cost-effectiveness analysis confirmed that pharmacist-led MedRec had the highest expected net benefits among interventions used to reduce medication errors at admission. ${ }^{26}$ There is currently no formalized process for pharmacists to conduct MedRec at the study hospital, although efforts are made to obtain BPMHs for high-risk patients with multiple comorbidities and/or multiple medications before admission. Incorporating pharmacy technicians into the admission MedRec process would be a feasible option to make such pharmacy services available to more patients. Multiple studies have shown that, with proper training, pharmacy technicians can collect complete and accurate BPMHs while identifying medication discrepancies for pharmacists to resolve as necessary. ${ }^{24,25,27}$

This study had several limitations. First, because of the retrospective nature of the study, it was not possible to verify the accuracy of the documented warfarin BPMHs. Furthermore, it was not possible to interview the clinicians to determine their methods of obtaining medication histories and to confirm the reasons for incomplete BPMH documentation. Finally, the sample size was insufficient to assess the effect of MedRec on warfarin-related clinical outcomes, such as thromboembolic and bleeding events. Therefore, future larger studies are needed to evaluate the accuracy of BPMH documentation, to determine the challenges of using the MedRec form, and to examine the utility of MedRec with regard to clinical outcomes.

\section{CONCLUSION}

In this study, implementation of PharmaNet-based admission MedRec was associated with a statistically significant increase in the rate of complete warfarin BPMH documentation. This finding suggests that the PharmaNet-based admission MedRec form can be a useful tool in standardizing the MedRec process. However, the clarity of PharmaNet records for warfarin was found to influence the quality of warfarin BPMHs. To ensure that BPMHs accurately reflect patients' home medication use, clinicians must be aware that PharmaNet records cannot be used as a substitute for BPMH and that PharmaNet records must be verified carefully upon admission to hospital.

\section{References}

1. Tam VC, Knowles SR, Cornish PL, Fine N, Marchesano R, Etchells EE. Frequency, type and clinical importance of medication history errors at admission to hospital: a systematic review. CMAJ. 2005;173(5):510-5.
2. Cornish PL, Knowles SR, Marchesano R, Tam V, Shadowitz S, Juurlink DN, et al. Unintended medication discrepancies at the time of hospital admission. Arch Intern Med. 2005;165(4):424-9.

3. Required organizational practices September 2011. Ottawa (ON): Accreditation Canada; 2011 [cited 2016 Sep 10]. Available from: http://jgh.ca/ uploads/Accreditation/ROPHandbook_EN.pdf

4. Hylek EM. Vitamin $\mathrm{K}$ antagonists and time in the therapeutic range: implications, challenges, and strategies for improvement. J Thromb Thrombolysis. 2013;35(3):333-5.

5. Van Walraven C, Oake N, Wells PS, Forster AJ. Burden of potentially avoidable anticoagulant-associated hemorrhagic and thromobembolic events in the elderly. Chest. 2007;131(5):1508-15.

6. Masaki N, Suzuki M, Matsumura A, Maruyama Y, Hashimoto Y. Quality of warfarin control affects the incidence of stroke in elderly patients with atrial fibrillation. Intern Med. 2010;49(16):1711-6.

7. Baker WL, Cios DA, Sander SD, Coleman CI. Meta-analysis to assess the quality of warfarin control in atrial fibrillation patients in the United States. JManag Care Pharm. 2009;15(3):244-52.

8. ISMP list of high-alert medications in acute care settings. Horsham (PA): Institute for Safe Medication Practices; 2014 [cited 2016 Jan 10]. Available from: www.ismp.org/Tools/highalertmedications.pdf

9. Schulman S, Kearon C. Definition of major bleeding in clinical investigations of antihemostatic medicinal products in nonsurgical patients. $J$ Thromb Haemost. 2005;3(4)692-4.

10. Barnsteiner JH. Chapter 38: Medication reconciliation. In: Hughes RG, editor. Patient safety and quality: an evidence-based handbook for nurses. Rockville (MD): Agency for Healthcare Research and Quality; 2008. Available from: www.ncbi.nlm.nih.gov/books/NBK2648/

11. FitzGerald RJ. Medication errors: the importance of an accurate drug history. Br J Clin Pharmacol. 2009;67(6):671-5.

12. Giménez-Manzorro Á, Romero-Jiménez RM, Calleja-Hernández MÁ, Pla-Mestre R, Muñoz-Calero A, Sanjurjo-Sáez M. Effectiveness of an electronic tool for medication reconciliation in a general surgery department. Int J Clin Pharm. 2015;37(1):159-67.

13. Zoni AC, Durán García ME, Jiménez Muñoz AB, Salomón Pérez R, Martin P, Herranz Alonso A. The impact of medication reconciliation program at admission in an internal medicine department. Eur J Intern Med. 2012; 23(8):696-700.

14. Rodehaver C, Fearing D. Medication reconciliation in acute care: ensuring an accurate drug regimen on admission and discharge. Jt Comm J Qual Patient Saf. 2005;31(7):406-13.

15. Wang T, Biederman S. Enhance the accuracy of medication histories for the elderly by using an electronic medication checklist. Perspect Health Inf Manag. 2012;9:1-15.

16. Kalb K, Shalansky S, Legal M, Khan N, Ma I, Hunte G. Unintended medication discrepancies associated with reliance on prescription databases for medication reconciliation on admission to a general medical ward. Can J Hosp Pharm. 2009;62(4):284-9.

17. Shalansky S, Jang L, Ignaszewski A, Clark C, Jung L, Marra C. Accuracy of a prescription claims database for medication reconciliation for outpatients with heart failure. Can J Hosp Pharm. 2007;60(3):169-76.

18. Price M, Bowen M, Lau F, Kitson N, Bardal S. Assessing accuracy of an electronic provincial medication repository. BMC Med Inform Decis Mak. 2012;12(1):42.

19. Mueller SK, Sponsler KC, Kripalani S, Schnipper JL. Hospital-based medication reconciliation practices: a systematic review. Arch Intern Med. 2012;172(14):1057-69.

20. Vasileff HM, Whitten LE, Pink JA, Goldsworthy SJ, Angley MT. The effect on medication errors of pharmacists charting medication in an emergency department. Pharm World Sci. 2008;31(3):373-9.

21. Hayes BD, Donovan JL, Smith BS, Hartman CA. Pharmacist-conducted medication reconciliation in an emergency department. Am J Health Syst Pharm. 2007;64(16):1720-3.

22. Nester TM, Hale LS. Effectiveness of a pharmacist-acquired medication history in promoting patient safety. Am J Health Syst Pharm. 2002;59:2221-5.

23. Murphy EM, Oxencis CJ, Klauck JA, Meyer DA, Zimmerman JM. Medication reconciliation at an academic medical center: implementation 
of a comprehensive program from admission to discharge. Am J Health Syst Pharm. 2009;66(23):2126-31.

24. Smith SB, Mango MD. Pharmacy-based medication reconciliation program utilizing-pharmacists and technicians: a process improvement initiative. Hosp Pharm. 2013;48(2):112-9.

25. Gardella JE, Cardwell TB, Nnadi M. Improving medication safety with accurate preadmission medication lists and post discharge education. $J t$ Comm J Qual Patient Saf. 2012;38(10):452-8.

26. Karnon J, Campbell F, Czoski-Murray C. Model-based cost-effectiveness analysis of interventions aimed at preventing medication error at hospital admission (medicines reconciliation). J Eval Clin Pract. 2009;15(2):299-306.

27. Remtulla S, Brown G, Frighetto L. Best possible medication history by a pharmacy technician at a tertiary care hospital. Can J Hosp Pharm. 2009; 62(5):402-5.

Debbie Au, BSc(Pharm), ACPR, is with Lower Mainland Pharmacy Services, Vancouver General Hospital, Vancouver, British Columbia.

Hilary Wu, BSC(Pharm), ACPR, is with Lower Mainland Pharmacy Services, St Paul's Hospital, Vancouver, British Columbia.

Cindy San, BSC(Pharm), ACPR, PharmD, is with Lower Mainland Pharmacy Services, St Paul's Hospital, Vancouver, British Columbia.
Doson Chua, BSc(Pharm), PharmD, BCPS(AQ), is with Lower Mainland Pharmacy Services, St Paul's Hospital, Vancouver, British Columbia.

Victoria Su, BSc(Pharm), ACPR, PharmD, BCPS, is with Lower Mainland Pharmacy Services, St Paul's Hospital, Vancouver, British Columbia.

Allison Kirkwood, BSC(Pharm), ACPR, is with Lower Mainland Pharmacy Services, St Paul's Hospital, Vancouver, British Columbia.

\section{Competing interests: None declared.}

\section{Address correspondence to:}

Debbie Au

G-42 Ground

Vancouver General Hospital

855 West 12th Avenue

Vancouver BC V5Z $1 \mathrm{M} 9$

e-mail: Debbie.au@vch.ca

Funding: None received.

Acknowledgements: The authors would like to acknowledge Stephanie Chan, BSC(Pharm), ACPR, for her expertise in medication reconciliation, and Angela Fung, BSc(Pharm), for assistance in data collection for this study.

\section{THERE'S ALWAYS MORE TO LEARN!}

Renew your membership today

From networking to education, our programs support you in your learning and career development.

\section{IL Y A TOUJOURS PLUS À APPRENDRE!}

Renouvelez votre adhésion dès aujourd'hui

Du résautage à la formation, nos programmes vous donnent une base solide pour continuer votre apprentissage et favoriser votre développement de carrière.
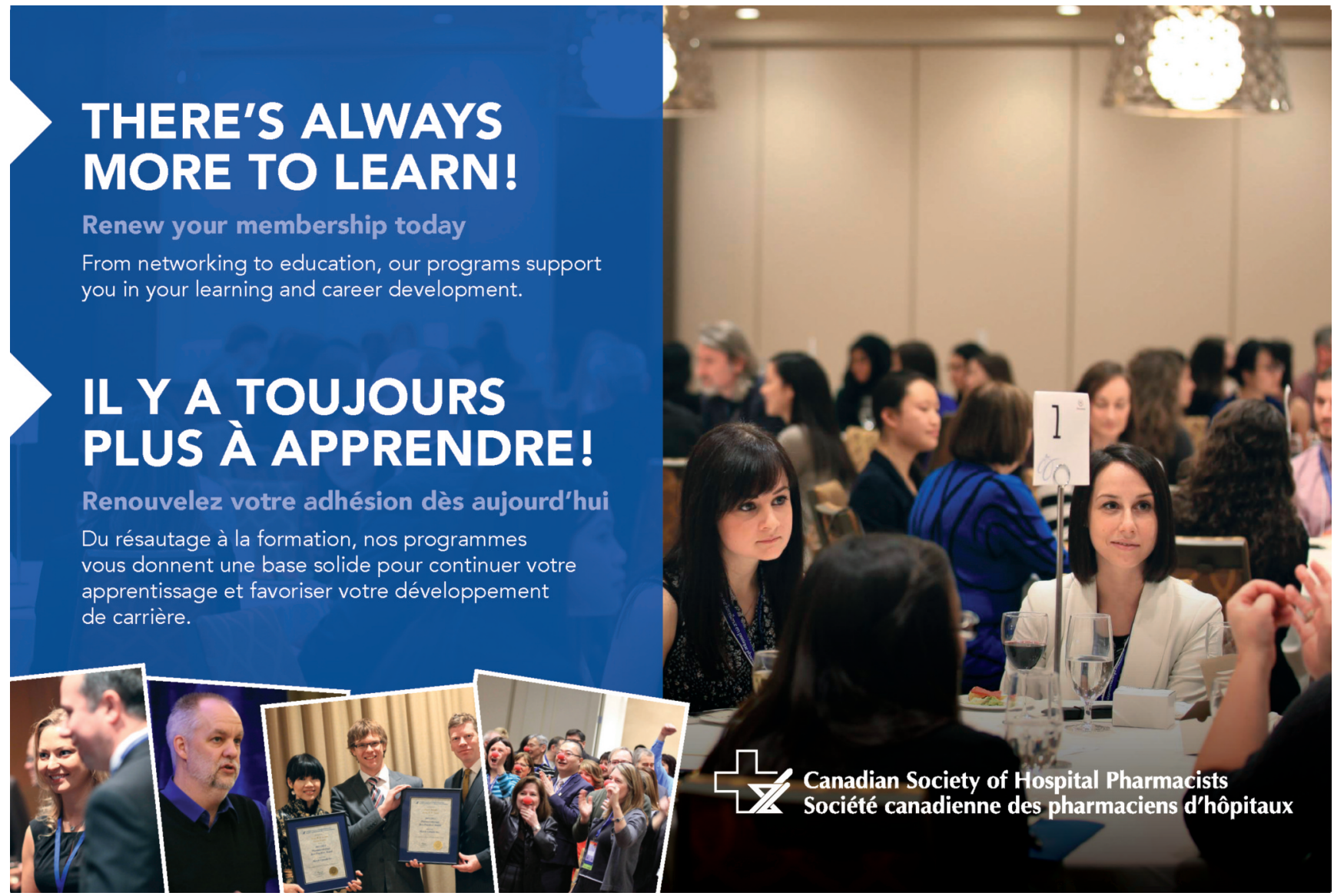